\title{
A trajetória arqueológica de Michel Foucault: caminhos possíveis
}

\begin{abstract}
Márcio Sales ${ }^{1}$
Resumo: $\mathrm{O}$ artigo é uma retomada da trajetória arqueológica de Michel Foucault e ao mesmo tempo uma homenagem aos 60 anos da História da Loucura, o livro inaugural desse percurso. Trata-se de um recorte em torno do tipo de história empreendido pelo autor, a arqueologia do saber, que consiste em fazer uma escavação dos diferentes discursos acerca da loucura, da medicina, da linguagem, das riquezas e da vida, desde o renascimento até à modernidade, a fim de analisar o modo como a sociedade ocidental, para fazer valer a sua razão, estabelecer a sua moral e impor a sua ordem, precisou afastar para longe tudo aquilo que representava o desconhecido, o diferente, o outro, enfim, a experiência outra. No entanto, tal experiência, na perspectiva foucaultiana, não deixou de permanecer viva, por debaixo da história, como uma espécie de clamor pela liberdade, pelo pensamento de fora, através de uma linguagem estrangeira, plural, revolucionária, que ele encontra na literatura e num certo tipo de filosofia.
\end{abstract}

Palavras-chave: História. Arqueologia. Loucura. Saber. Possibilidade.

\section{Michel Foucault's archaeological trajectory: possible paths}

Abstract: The article is a commemoration of the 60th anniversary of History of Madness by Michel Foucault and also a cut around the type of history undertaken by the author, the archeology of knowledge, which consists in excavating the different discourses on madness, since the renaissance until modernity, aiming to analyse the way western society, in order to assert its reason, establish its morality and impose its order, had to push away everything that represented the unknown, the different, the other, in short, the tragic experience of madness. However, such experience, in the Foucaultian perspective, did not cease to remain alive, underneath history, as a type of clamor for freedom, for the outside thought, through a foreign, plural, revolutionary language, which he finds in literature.

Keywords: History. Archeology. Madness. Knowledge. Possibilities.

\section{La trayectoria arqueológica de Michel Foucault: posibles caminos}

Resumen: O El artículo es una conmemoración de los 60 años de la Historia de la locura de Michel Foucault y también un recorte en torno al tipo de historia emprendida por el autor, la arqueología del conocimiento, que consiste en investigar a fondo los diferentes discursos sobre la locura, desde el Renacimiento a modernidad, para analizar

\footnotetext{
${ }^{1}$ Doutor em Filosofia. Professor do Instituto Superior de Educação do Rio de Janeiro - ISERJ. E-mail: marcio.salles@yahoo.com.br. Orcid: https://orcid.org/0000-0001-8313-022X.
} 
la forma en que la sociedad occidental, para afirmar su razón, establecer su moralidad e imponer su orden, tuvo que alejar todo lo que representaba lo desconocido, lo diferente, lo otro, en definitiva, la trágica experiencia de la locura . Sin embargo, tal experiencia, en la perspectiva foucaultiana, no dejó de permanecer viva, debajo de la historia, como una especie de grito de libertad, de pensamiento exterior, a través de un lenguaje extranjero, plural, revolucionario, que encuentra en la literatura.

Palabras clave: Historia. Arqueología. Locura. Conocimiento. Posibilidades.

\section{Apresentação}

Reduzir algo de desconhecido ao que é conhecido alivia, tranqüiliza, satisfaz, dá, além disso, um sentimento de poder. No que é desconhecido reside o perigo, a inquietude, a preocupação - o instinto primário dirige-se a eliminar estes estados penosos. Nietzsche, "Os quatro grandes erros", Crepúsculo dos ídolos.

Há cerca de 60 anos, com o seu livro História da loucura (1961), Michel Foucault lançava um novo olhar para a história e povoava o universo da loucura, da medicina, da linguagem, das riquezas e da vida com novas paisagens e problematizações. Sua forma de abordagem arqueológica, sua narrativa multifacetada e o vigor de suas análises abriram caminho para um novo fazer filosófico.

O próprio Foucault não cansava de revisitar a sua própria trajetória arqueológica situando-a em meio ao trabalho que estava realizando em um dado momento e em outro contexto. Ora fazendo uma autocrítica e demarcando seus deslocamentos em relação a ela, ora ressaltando a sua relevância e tecendo novas combinações conceituais. É assim que se torna possível situar a questão da arqueologia no conjunto do pensamento de Foucault, sobretudo no sentido de um uso possível do pensamento, do discurso, da história e da liberdade.

\section{Uma história das condições de possibilidade}

A História da Loucura trata da exclusão do outro, do louco enquanto estrangeiro $^{2}$; entretanto, essa história é feita levando em consideração uma ocultação; a saber, do conteúdo trágico da loucura. Foucault não faz uma abordagem minuciosa desse elemento trágico, mas mostra como ele foi posto de lado, dado o privilégio concedido a uma experiência crítica e moral. Essa divisão entre uma experiência trágica

\footnotetext{
2“A história da loucura seria a história do Outro - daquilo que, para uma cultura é ao mesmo tempo interior e estranho, a ser portanto excluído (para conjurar-lhe o perigo interior), encerrando-o porém (para reduzir-lhe a alteridade)". (FOUCAULT, 1999).
} 
e uma experiência crítica da loucura é que vai orientar toda a sua análise. Ele vai mostrar que, num dado momento histórico, a experiência crítica e moral prevaleceu e se firmou como ordem; porém, antes dessa separação, as duas formas de experiência conviviam numa certa reciprocidade. Foucault pretende assim colocar em questão o momento em que a linguagem crítica de uma certa racionalidade histórica, para se firmar, conjurou a linguagem trágica da loucura, "antes mesmo que ela fosse definitivamente estabelecida no reino da verdade, antes mesmo que ela fosse reanimada pelo lirismo da protestação" (FOUCAULT, 1999, p. 159). Foucault pretende partir do que ele chama de "grau zero da história da loucura", ou seja, da loucura enquanto experiência indiferenciada, experiência ainda não dividida; da loucura em suas formas múltiplas antes de ser encerrada numa consciência crítica. Uma vez desenhada a oposição entre a experiência trágica e a experiência crítica da loucura, ela não mais será pensada em sua forma total, ou seja, em suas múltiplas faces, mas somente de forma parcial, na sua forma de anomalia e doença mental. Assim sendo, os saberes que se formam em torno da experiência da loucura só serão possíveis mediante esse afastamento das suas formas trágicas.

É assim que Foucault define a experiência clássica da loucura e através dela a moderna, como um conjunto desequilibrado por tudo aquilo de que carece; isto é, por tudo aquilo que oculta. Uma figura fragmentária que, de modo abusivo, se apresenta como exaustiva (FOUCAULT, 1997, p. 29). Ela apresenta-se como sendo a realidade total dos acontecimentos, mas sob o manto de sua verdade, uma outra experiência não deixa de se mexer e se inquietar. Com isso Foucault realiza a arqueologia de um silêncio. Ou seja, através da análise dos diferentes discursos acerca da loucura, ao longo da era clássica e da era moderna, opera uma cartografia de como funcionam, que tipo de comportamento produzem, que saberes permitem, que instituições fundamentam, e ainda, que imagens da loucura afastam, colocam na sombra, mergulham no silêncio.

Já em O nascimento da clínica (1963), ele diz fazer a arqueologia de um olhar. Um olhar em torno do espaço, da linguagem e da morte (FOUCAULT, 2013, p. VII). É que ver e saber se confundem. As formas de visibilidade interferem nas formas de saber. O olhar condicionado condiciona o saber. Na verdade, o visível e o enunciável lançam as bases de um determinado conhecimento médico e que se estende ao conhecimento do ser humano. "Foi preciso abrir a linguagem a todo um domínio novo: o de uma correlação contínua e objetivamente fundada entre o visível e o enunciável. Definiu-se 
então um uso absolutamente novo do discurso científico" (FOUCAULT, 2013, p. 226). Um discurso fundante da ideia de homem, de homem saudável e homem normal. "Podese compreender, a partir daí, a importância da medicina para a constituição das ciências do homem: importância que não é apenas metodológica, na medida em que ela diz respeito ao ser do homem como objeto de saber positivo" (FOUCAULT, 2013, p. 227). Será no livro seguinte, As palavras e as coisas, que Foucault utilizará o termo "arqueologia de um olhar médico" para definir o tipo de investigação realizado em $O$ nascimento da clínica.

O subtítulo de As palavras e as coisas (1966) é uma arqueologia das ciências humanas. O livro trata da experiência da ordem que fundamenta as palavras, as percepções e os gestos; ou seja, a linguagem tal como foi falada, o olhar sobre os seres naturais e suas devidas classificações e as práticas em torno das trocas de bens matérias e das riquezas. "A ordem é ao mesmo tempo aquilo que se oferece nas coisas como sua lei interior, a rede secreta segundo a qual elas se olham de algum modo umas às outras e aquilo que só existe através do crivo de um olhar, de uma atenção, de uma linguagem; e é somente nas casas brancas desse quadriculado que ela se manifesta em profundidade como já presente, esperando em silêncio o momento de ser anunciada" (FOUCAULT, 1999, p. XVI). Esta ordenação do mundo possibilita o surgimento de certas ciências humanas, que vão da gramática à filologia, da história natural à biologia, do estudo das riquezas à economia política. A arqueologia é o estudo desse espaço de ordem sobre o qual se constitui o saber sobre o homem. Espaço esse que Foucault chama de epistémê: “o que se quer trazer à luz é o campo epistemológico, a epistémê onde os conhecimentos, encarados fora de qualquer critério referente a seu valor racional ou a suas formas objetivas, enraízam sua positividade e manifestam assim uma história que não é a de sua perfeição crescente, mas, antes, a de suas condições de possibilidade; neste relato, o que deve aparecer são, no espaço do saber, as configurações que deram lugar às formas diversas do conhecimento empírico. Mais que de uma história no sentido tradicional da palavra, trata-se de uma "arqueologia"” (FOUCAULT, 1999, p. XVIII-XIX). Desse modo, a análise arqueológica circunscreve as condições de possibilidade de um saber, os seus limites e a passagem para outra organização epistêmica: "a arqueologia, dirigindo-se ao espaço geral do saber, a suas configurações e ao modo de ser das coisas que aí aparecem, define sistemas de simultaneidade, assim 
como a série de mutações necessárias e suficientes para circunscrever o limiar de uma positividade nova" (FOUCAULT, 1999, p. XX).

É nesse sentido que o homem aparece como uma invenção recente; uma vez que é o resultado de um conjunto de saberes que o isola, o examina e o determina em sua positividade. Mas como esta ordem epistemológica é transitiva, ela aponta para novos estatutos que começam a se desenhar e sugerem a morte deste homem moderno: "é um reconforto e um profundo apaziguamento pensar que o homem não passa de uma invenção recente, um figura que não tem dois séculos, uma simples dobra de nosso saber, e que desaparecerá desde que este houver encontrado uma nova forma" (FOUCAULT, 1999, p. XXI). O que está em jogo na análise arqueológica é o "limiar que nos separa do pensamento clássico e constitui nossa modernidade" (FOUCAULT, 1999, p. XXII). E com isso sinalizar a transitoriedade dos saberes e das experiências. Sem dúvida, um olhar para o que somos, mas sobretudo para o que podemos nos tornar. Para as possibilidades de um saber outro, apoiado em outra forma de racionalidade (epistémê) e, portanto, abrindo espaço para novas experiências de nós mesmos. Uma análise do território tendo em vista a desterritorialização. A análise do nosso rosto na areia na expectativa de que a onda venha, arraste esse rosto e possibilite novas rostidades.

\section{Uma história crítica da História}

A história ocidental, na concepção de Foucault, é o resultado de uma seleção de elementos, fatos, acontecimentos e experiências que tem como critérios os parâmetros definidos por uma lógica determinada e determinante. Uma história escrita de forma que tenha um sentido e que esse sentido se encaixe perfeitamente com a lógica da razão dominante, que por sua vez corresponde aos valores de uma cultura. É assim que uma sociedade regida pelos privilégios da razão possui a história que lhe convém. No entanto, essa história não representa a realidade como um todo. Ela nada mais é do que uma maneira de produzir uma realidade; uma forma de percepção que orienta o olhar e delimita uma visão de mundo. Contudo, à luz da cultura dominante ela é a própria retratação da verdade; e para se afirmar como tal ela precisa excluir do seu horizonte o que não se harmoniza com os seus interesses. Ela esconde uma outra realidade considerada menor e por isso indigna de configurar nas páginas da história. 
É assim que a análise crítica de Foucault suscita algumas questões tais como: “o que significa este confronto por baixo da linguagem da razão? Em que direção poderia nos conduzir uma interrogação que não seguisse a razão no seu devir horizontal, mas que procurasse retraçar no tempo esta verticalidade constante que, ao longo de toda cultura europeia, a confronta com o que ela não é, a medida para sua própria desmedida? Para que região nós iremos que não é nem história do conhecimento, nem simplesmente história, que não é comandada nem pela teleologia da verdade, nem pelo encadeamento racional das causas, as quais não tem valor e sentido que estejam além da divisão? Uma região sem dúvida, que seja mais uma questão de limites do que de identidade de uma cultura" (FOUCAULT, 1997, p. 161). A história arqueológica de Foucault, ao invés de seguir uma horizontalidade que recorta, suspende e oculta certos elementos para por outros em evidência, opera uma transversalidade no sentido de chamar a atenção para as diferentes dobras da história, suas diferentes interpretações, seus jogos de verdade, suas relações de poder, suas linhas de fuga e seu devir revolucionário.

\section{Uma história dos limites}

Foucault distingue a sua história e a situa numa região que é a dos limites. $\mathrm{O}$ limite que separa uma coisa do que ela não é - por exemplo, a razão da desrazão. Ele diz que se poderia fazer a história dos limites, desses gestos obscuros, necessariamente esquecidos desde que concluídos, pelos quais uma cultura rejeita qualquer coisa que será para ela o exterior, e tudo ao longo de sua história. Esse vazio escavado, esse espaço em branco pelo qual ela se isola, designa nada mais que seus valores. Esses valores ela os recebe e os mantém na continuidade da história.

Os valores de uma cultura delineiam seus limites; demarcam o que é positivo e o que é negativo, o que deve ser preservado e o que deve ser excluído. Os valores orientam uma escolha. É o que diz Foucault: "nessa região da qual nós podemos falar, ela (a cultura) exerce suas escolhas essenciais, faz a divisão que constrói o rosto da sua positividade; nela se encontra a espessura originária onde ela se forma. Interrogar uma cultura sobre suas experiências-limites, é questioná-la, aos confins da história, sobre um despedaçamento que é como o nascimento mesmo da sua história”. (FOUCAULT, 1997, p. 161). 
O gesto que divide - que implica em uma escolha decisiva - é o gesto que corresponde ao movimento da dobra, como dirá Foucault, indicando a dobra que resulta na ocultação da dobra. Trata-se da "organização da unidade fechada do presente; a percepção que o homem ocidental tem de seu tempo e de seu espaço deixa aparecer uma estrutura de rejeição, a partir da qual se denuncia uma palavra como não sendo linguagem, um gesto como não sendo obra, uma figura como não tendo o direito de ocupar lugar na história”. (FOUCAULT, 1997, p.163).

Foucault denuncia a história dominante como sendo excludente, possuindo uma estrutura de rejeição, selecionando o que lhe convém e descartando o que não é do seu interesse. A história compõe uma ordem - o que Foucault chama de unidade fechada do presente. A história assim pensada como um discurso da verdade, como um domínio do olhar, como uma totalidade dos fatos tende a sucumbir o diferente, transformando-o em algo destoante e ameaçador.

É assim que a loucura é excluída como linguagem perigosa. Ela apresenta uma face que por ser considerada sombria, é posta à margem da história. A loucura passa ser algo exterior à razão; e só é exterior uma vez que foi interiorizada, dominada, possuída.

Dessa forma a história é escrita ocultando um elemento considerado pelo crivo da razão inferior e dispensável para a história. Ela se dobra escondendo o que não lhe convém; entretanto, para além da sua curvatura existe uma outra face. O que Foucault pretende é desdobrar a história da loucura denunciando essa ocultação. Trata-se de uma tarefa difícil e até perigosa; pois essa região onde acontece a curvatura é uma região incômoda. Foucault diz que para percorrê-la é preciso "renunciar ao conforto das verdades terminais e não se deixar jamais guiar pelo que nós podemos saber da loucura". (FOUCAULT, 1997, p. 159). É incômodo porque requer um abandono do que já se sabe sobre a loucura e um exercício do pensamento que escape de uma lógica identitária e totalizadora. Consiste em por em prática uma racionalidade outra, impulsionada pela afirmação da diferença e potencializada pela criação de um novo estatuto para experiência da loucura, que Foucault chamará de experiência trágica.

É nesse sentido que Foucault revoluciona a história; porque ao mesmo tempo em que a desarma, ele questiona a sua obviedade. Desmantela sua unidade fechada, evocando novos sentidos. Como arqueólogo escava os solos e subsolos da história desnudando-os. Utilizando a linguagem figurada de Paul Veyne, ele trás à tona a "parte oculta do iceberg", ou seja, Foucault não inventa uma nova história, mas traz para a 
superfície uma teia discursiva múltipla e dispersiva; "ele nos convida a observar, com exatidão, o que assim é dito". (VEYNE, 1998, p. 251-252).

\section{Uma história das relações}

A História da Loucura percorre um caminho que vai do gesto que divide ao gesto que exclui, deixando em suspenso tudo o que poder fazer figurar a perfeição, o repouso da verdade. Falando desse gesto de corte, dessa distância tomada, desse vazio instaurado entre a razão e o que ela não é, sem jamais se apoiar sobre a plenitude do que ela pretende ser (FOUCAULT, 1997, p. 160). Foucault diz que na região em que situa a sua análise, "loucura e não-loucura, razão e não-razão são confusamente implicadas: inseparáveis do momento que elas não existem ainda, e existente uma para outra, uma em relação à outra, na troca que as separa”. (FOUCAULT, 1997, p. 160). Essa relação de reciprocidade e até de cumplicidade é possível ser percebida no momento anterior à divisão, onde loucura e razão participam de uma linguagem bem mais original, mais matinal que a da ciência, que por sua vez só irá se firmar pela conjuração da experiência trágica da loucura.

A história arqueológica se apoia no conflito de forças, nos antagonismos que marcam os saberes, as práticas e as instituições, nas relações que compreendem modos de subjetivação distintos e múltiplos. Trata-se de uma prática histórica que chama a atenção para a relação de reciprocidade entre as partes: o normal só é definido na sua relação de exclusão, mas sobretudo de implicação, do que é tido como anormal. O anormal se torna o ponto de referência para a constituição do normal. Através da atribuição do seu sentido (lógica do sentido), do desenho do seu rosto (rostidade), da circunscrição do seu território (territorialização), afirma-se uma distância e uma condição para afirmar-se a si mesmo como modelo de existência.

\section{Uma história da experiência de exclusão}

Fundamentado na ideia de progresso científico, o homem moderno não se comunica mais com o louco. Há de um lado o homem da razão que orienta a loucura em direção à medicina, o homem que detém a loucura em sua verdade e, por outro lado, o homem da loucura que não se comunica com aquele outro; por ser o seu objeto de análise. Assim sendo, por intermédio da razão, ele é abstraído da ordem, constrangido física e moralmente; constitui-se um anônimo pressionado numa sociedade que exige 
dele conformidade. Foucault mostra que a constituição da loucura como doença mental, no final do século XVIII, constata de uma vez por todas o rompimento de um diálogo entre razão e loucura. Prevalece apenas uma fala: a da ciência. É assim que Foucault define a linguagem da psiquiatria como sendo o monólogo da razão sobre a loucura; linguagem esta que não pode se estabelecer senão sobre tal silêncio. (FOUCAULT, 1997, p. 160). A arqueologia de Foucault não é a história dessa linguagem, mas desse silêncio. (FOUCAULT, 1997, p. 160). Não se trata portanto de uma história do conhecimento, mas dos movimentos rudimentares de uma experiência. Sua luta contra as verdades da psiquiatria (psicopatologia) não é para apresentar uma verdade mais verdadeira, mas para mostrar as condições que a tornaram possível. Condições que apontam para uma divisão original e, a partir dela, para uma exclusão radical. Neste sentido, esta história não é feita através dos conceitos científicos, mas tomando como ponto de partida a constituição do gesto que divide a loucura. (FOUCAULT, 1997, p. 159).

Para Foucault, a psiquiatria só foi possível devido a essa divisão que estabeleceu, de uma vez por todas, a distância entre razão e não-razão; e que possibilitou que a razão exercesse um domínio sobre a loucura, para extrair dela a sua verdade; seja como falta ou como doença.

Foucault dirá que "é preciso prestar muita atenção, inclinar-se para o murmúrio do mundo, esforçar-se para perceber tanto as imagens que nunca foram poesia como os fantasmas que nunca atingiram as cores da vigília". Mas essa tarefa é duplamente impossível: "porque ela requereria uma demora para reconstituir a poeira dessas dores concretas, dessas palavras insensatas que não se prendem ao tempo; e porque sobretudo essas dores e palavras não existem e não são dadas à elas mesmas e aos outros senão no gesto da divisão que já as denuncia e as domina. É somente no ato da separação e a partir dele que se pode pensar como poeira ainda não separada”. A percepção que procura agrupá-las ao estado selvagem pertence necessariamente a um mundo que já as tem como capturadas. A liberdade da loucura não é possível senão do alto da fortaleza que a tem como prisioneira. Dirá Foucault: “Ora, ela dispõe senão do tristonho estado civil de suas prisões, de sua experiência muda de perseguida, e nós não temos senão o seu sinal de evadida”. (FOUCAULT, 1997, p. 164).

Se é possível falar da divisão original, esta possibilidade deixa de existir quando se trata de pensar a loucura em seu estado livre - primitivo - em sua expressão múltipla, 
antes da divisão. Pensar a loucura só é possível a partir do gesto que a divide. Pensá-la enquanto já dominada e excluída. Pensá-la na perspectiva da denúncia, do combate, da resistência, da insubmissão.

\section{Uma história descritiva dos discursos}

Ao tratar do discurso em sua aula inaugural no College de France, Foucault fala de uma voz sem nome que o precede. O seu próprio discurso como que fazendo parte de uma episteme, de uma camada de saber ou um conjunto de platôs. Mas esse pertencimento não se traduz numa calmaria dos saberes. Antes, num campo permanente de tensão, numa espécie de agitação em alto mar, que nos lança já para uma nova fronteira do próprio saber e na possibilidade de novos discursos - "o novo não está no que é dito, mas no acontecimento de sua volta" (FOUCAULT, 1998, p. 26). É a própria transitoriedade do olhar e do falar. Essa mistura que junta os saberes constituídos (a ordem do discurso) e os enunciados que desenham uma nova paisagem (o fluxo do pensamento). De qualquer modo, um jogo que envolve poderes e perigos: "em toda sociedade a produção do discurso é ao mesmo tempo controlada, selecionada, organizada e redistribuída por certo número de procedimentos que têm por função conjurar seus poderes e perigos, dominar seu acontecimento aleatório, esquivar sua pesada e temível materialidade" (FOUCAULT, 1998, p. 9). Poderes que impõem uma palavra de ordem, mas também poderes ou potências que deslocam o olhar e o falar para outro lugar, para o fora da ordem, para o pensamento de fora. Perigos que se referem às formas de controle e normalização, mas também perigos que ameaçam a própria ordem instituída pelas linhas de fuga que são inventadas. No entanto, esses poderes e perigos relacionados ao desconhecido são conjurados por mecanismos de exclusão, de interdição, de rejeição, de separação; numa batalha discursiva entre o verdadeiro e o falso. É nesse sentido que é possível falar de um saber autorizado, um saber legitimado como saber: "o saber é aplicado em uma sociedade, como é valorizado, distribuído, repartido e de certo modo atribuído" (FOUCAULT, 1998, p. 17). Mas a arqueologia do saber não se prende a esses saberes legítimos, mas toma como saber toda sorte de enunciados, analisados em sua materialidade. Ou seja, por um lado um tipo de discurso institucionalizado que procura centralizar os saberes e, por outro, um tipo de discurso mais disperso que se apresenta em sua expressão múltipla. "Creio que essa vontade de verdade assim apoiada sobre um suporte e uma distribuição institucional tende a exercer 
sobre os outros discursos - estou sempre falando de nossa sociedade - uma espécie de pressão e como que um poder de coerção" (FOUCAULT, 1998, p. 18). Foucault assim chama a atenção para a vontade de verdade e, sobretudo, para o desejo e o poder que alimentam essa vontade de verdade. O saber legítimo, tido como verdadeiro, conjura outros discursos considerados falsos ou destituídos de razão, discursos que beiram à loucura, e que pela ameaça que representam, são conjurados. Essa circunscrição do saber verdadeiro, à luz da análise arqueológica, é acompanhada de uma vontade de verdade que é também uma forma de dominação, isto é, de exercício de poder e exclusão. "Assim, só aparece aos nossos olhos uma verdade que seria riqueza, fecundidade, força doce e insidiosamente universal. E ignoramos, em contrapartida, a vontade de verdade, como prodigiosa maquinaria destinada a excluir todos aqueles que, ponto por ponto, em nossa história, procuraram contornar essa vontade de verdade e recolocá-la em questão contra a verdade, lá justamente onde a verdade assume a tarefa de justificar a interdição e definir a loucura; todos aqueles, de Nietzsche a Artaud e a Bataille, devem agora nos servir de sinais, altivos sem dúvida, para o trabalho de todo dia" (FOUCAULT, 1998, p. 21). A própria educação exerce esse papel de apropriação dos discursos verdadeiros e de uma ordenação dos saberes. "Sabe-se que a educação, embora seja, de direito, o instrumento graças ao qual todo indivíduo, em uma sociedade como a nossa, poder ter acesso a qualquer tipo de discurso, segue, em sua distribuição, no que permite e no que impede, as linhas que estão marcadas pela distância, pelas oposições e lutas sociais. Todo sistema de educação é uma maneira política de manter ou de modificar a apropriação dos discursos, com os saberes e os poderes que eles trazem consigo" (FOUCAULT, 1998, p. 44). A análise arqueologia, nesse sentido, opera um deslocamento ou um descentramento, abordando os discursos em sua dispersão, em sua transversalidade, tanto os discursos centrais quanto os marginais, apreendendo-os em sua materialidade, ou seja, na medida em que são ditos ou escritos, ou até mesmo, expressos na forma de imagem. Trata-se de uma análise crítica na medida em que denuncia a vontade de verdade, os efeitos dela decorrente, bem como a soberania de um significante: "questionar nossa vontade de verdade; restituir ao discurso seu caráter de acontecimento; suspender, enfim, a soberania do significante" (FOUCAULT, 1998, p. 51). Por acontecimento discursivo Foucault entende o "âmbito da materialidade que ele se efetiva, que é efeito; ele possui seu lugar e consiste na relação, coexistência, dispersão, recorte, acumulação, seleção de elementos materiais" 
(FOUCAULT, 1998, p. 57). São as conjugações dos discursos e seus desdobramentos; seus efeitos e suas intensidades; seus jogos e suas potências.

\section{Uma história problematizadora}

A história da loucura é um estudo problematizador da totalidade histórica noções, instituições, medidas jurídicas e policiais, conceitos científicos - que mantém cativa uma loucura cujo estado selvagem não pode ser restituído nele mesmo; mas na ausência dessa inacessível pureza primitiva, o estudo arqueológico deve remontar para a decisão que liga e separa, ao mesmo tempo, razão e loucura; e deve procurar descobrir a reciprocidade perpétua, a obscura raiz comum, o confronto original que dá sentido à unidade, bem como à oposição entre sensato e insensato. Foucault diz que desse modo "poderá reaparecer a decisão fulgurante, heterogênea no tempo da história, mas inapreensível fora dele, que separa da linguagem da razão e das promessas do tempo este murmúrio de insetos sombrios". (FOUCAULT, 1997, p. 164).

Foucault pretende mostrar que o estatuto da loucura na modernidade - a loucura enquanto doença mental - se distancia da experiência que se tinha da loucura durante a Renascença, indicando com isto não o que se pretende afirmar; a saber, a descoberta progressiva, pela ciência e pela filantropia, da loucura na sua verdade positiva e consequentemente a sua libertação; mas, antes, a repressão cega num regime absolutista, um confinamento da loucura num estatuto que a encerra de vez num silêncio profundo. Foucault dirá que a Idade Clássica "cobre justamente esse período onde a reciprocidade entre a loucura e a razão modifica sua linguagem, e de maneira radical". (FOUCAULT, 1997, p. 164-165)

Dois acontecimentos assinalam essa alteração com clareza: a criação do Hospital Geral e o "Grande Enclausuramento" em 1657 e a libertação dos encarcerados de Bicêtre em 1794. Aparentemente de um para o outro acontece uma verdadeira revolução, uma grande libertação. Mas não devemos nos deixar levar pelas evidências dos fatos. O que Foucault mostra é que de um para o outro o domínio da loucura pela razão é levado até as suas últimas conseqüências - a loucura é encerrada no mais profundo silêncio.

A divisão que atravessa a experiência clássica da loucura está ligada também ao encerramento do homem num potente esquecimento. Ela ordena o sol da verdade para a frágil luz da sua verdade. A psicologia se arvora a dizer a verdade do homem: a verdade 
do homem por ele mesmo. Foucault vê nisso um modo de dominação do homem; e mais ainda, a inscrição do homem numa ordem moral que lhe é imposta, escondida atrás de uma ordem positiva da razão - da dita ciência do homem. Para Foucault, a apropriação do homem pelas ciências humanas corresponde a um controle da liberdade.

Neste sentido, a História da Loucura se inscreve num projeto que indica as condições de possibilidade da psicologia. Em última análise, ela não seria possível se não fosse estabelecida uma divisão original. "Na constituição desta experiência da loucura, uma história das condições de possibilidade da psicologia é escrita como dela mesma". (FOUCAULT, 1997, p. 166).

\section{Uma história arqueológica}

Em História da Loucura Foucault inaugura uma nova forma de história que se distingue tanto das histórias das ideias ou das ciências, como também da história epistemológica. É o que ele chama de arqueologia. Reivindicando sua independência com relação a qualquer ciência, a arqueologia pretende ser uma crítica da própria ideia de racionalidade. Investigando a condição de existência dos saberes, através da análise do que dizem, como dizem e por que dizem, a arqueologia neutraliza a questão da cientificidade. Desta forma, ela opera um deslocamento de uma região do conhecimento para uma outra que compreende os discursos, as práticas e as instituições. Esse deslocamento é provocado pelos objetos da análise arqueológica. Em História da Loucura a especificidade do objeto de estudo foi determinante para a formulação e exercício de um tipo de abordagem história que procura situar seu espaço próprio através de um debate com os outros tipos de história. Neste sentido, o objeto da arqueologia não só não é a ciência como também não tem a ciência como critério. A arqueologia não estabelece uma demarcação entre ciência e pré-ciência ou conhecimento comum; não se limita a uma disciplina científica aceitando suas regras nem tampouco se limita à análise dos discursos que pretendem ter cientificidade; ela leva em consideração discursos filosóficos, teológicos, poéticos, literários etc. Para ela, a concepção da loucura em diferentes épocas não é exclusividade de nenhum tipo específico de texto ou disciplina. A questão da loucura é um fio condutor onde a análise leva em consideração um conjunto de experiências que constitui como objeto.

O que pretende a arqueologia é dar conta da produção de um tipo de conhecimento que, por suas características intrínsecas, não pode ser estudado com 
proveito pela epistemologia, na medida em que não é um discurso propriamente científico. Como aponta o próprio Foucault, a palavra arqueologia designa a “especificação de um nível - o do enunciado e do arquivo; determinação e esclarecimento de um domínio: as regularidades enunciativas, as positividades". (FOUCAULT, 1987, p. 234). Trata-se de um nível que atinge a sensibilidade, ou seja, as formas estruturadas da experiência que tornam possíveis os discursos, as práticas e as instituições; portanto, um nível que vai além dos limites da ciência, em que a linguagem é "livre de terminologia científica e de opções morais ou sociais". (FOUCAULT, 1997, p. 166). A arqueologia pretende ser um discurso livre, sem fronteiras, que escapa ao jogo de formação dos enunciados. As investigações arqueológicas são verticais no sentido de levar em consideração e articular níveis diferentes de análise que envolve inclusive as instituições; como ocorre em História da Loucura em que a verticalidade da análise diz respeito ao saber diretamente ligado à experiência, ou seja, à maneira como uma determinada época concebeu a experiência da loucura.

\section{Loucura, caos e caosmofagia}

Lançar mão de uma nova forma de escrever a história, com um outro tipo de racionalidade envolvida, consiste em se afastar de tantas outras que não se afinam com a proposta em questão. É assim que já na sua História da loucura Foucault se empenhava em fazer uma crítica da Razão. Um tipo de razão dominadora que pressupunha uma verdade ordenadora. Muitos o acusaram de irracionalista e de defender uma experiência da loucura. Ora, não se trata de irracionalismo. Identificar loucura e irracionalidade só faz sentido se se pensar em termos de uma outra forma de racionalidade não reduzida às formas definidas por uma cientificidade dominante. A experiência da loucura, que para Foucault é, sobretudo, uma experiência da linguagem e do pensamento, implica em outro tipo de logos, de pensamento e de expressão que está o tempo inteiro aberto ao novo, ao fora, ao que está por vir. Um logos que é também um fluxo e um caos. Um plano de imanência que corta o caos e o transporta para o pensamento.

Esse tipo de experiência pode ser encontrado, por exemplo, na literatura. Para Foucault, literatura e loucura, a despeito da racionalidade predominante, mantém uma certa relação que envolve uma abertura para a multiplicidade dos sentidos. Por isso a loucura diz respeito a um outro logos, a uma outra forma de linguagem que Foucault chama de linguagem sem apoio. Uma linguagem nômade, desterritorializada, aberta 
para o desconhecido. Uma linguagem caosmofágica, uma vez que devora tudo o que vê pela frente, instaurando um discurso multifacetado e plural. Literatura, pintura, poesia, ciência, decretos, leis, normas... tudo é devorado nessa experiência tragicaosomofágica.

Para além do visto e do dito, a experiência da loucura aponta para o invisível e para o silêncio - é o lugar do impensado. Porém, impensado não quer dizer não vivido. Há sempre uma experiência que nos cerca e nos acompanha e que não se reduz ao nosso campo de pensamento. Há sempre uma potência que nos arrasta para outro lugar, para outra direção, para o que não é ainda a nossa experiência, mas que, nesse gesto mesmo, já constitui uma nova experiência. É que para Foucault a ontologia do presente deve chamar a atenção não apenas para o que somos, mas principalmente para o que estamos em via de nos tornar.

É assim que Foucault insiste em afirmar que faz uma história da verdade. Fazer a história da verdade é traçar uma linha que define uma experiência: de percepção, de saber e de práticas, numa certa época e sociedade. O jogo da verdade é portanto repleto de nuances que aparecem vinculadas à ordem da razão, da moral, da política, da economia etc. Foucault não rejeita a verdade. O que faz é mostrar que toda verdade é um jogo político, uma batalha, uma decisão. No caso da verdade amparada na razão moderna, trata-se de uma verdade tida como base sólida e segura de uma experiência científica do saber.

O que é a verdade? Um jogo ou ainda o efeito de um jogo; efeito de superfície por isso ligado à máscara. Toda verdade é ao mesmo tempo mascarada e translúcida. É que não há realidade fora da aparência, fora da experiência. Neste sentido, toda verdade é uma invenção, uma criação e não adequação das palavras às coisas. A verdade é o que dá sentido às coisas; é o jogo estratégico na ordem do mundo.

Com isto, podemos pensar que a crítica que Foucault faz à razão, à moral e à verdade não é uma crítica apriori a esses conceitos. São críticas históricas, ao uso desses conceitos, a experiência que representam. Por razão entenda-se um tipo de racionalidade; por moral um tipo de julgamento e por verdade uma forma de ordenação do mundo.

Se Foucault abandona ao longo de sua obra a noção de experiência trágica não significa isto um abandono de uma postura trágica. A experiência trágica da loucura aparecia vinculada a uma experiência da linguagem, própria da literatura. Talvez 
Foucault tenha deixado de ver na literatura uma arma política apropriada para o combate a que se propunha. Talvez tenha encontrado outros caminhos mais eficazes. É sempre o uso concreto, político, pragmático do pensamento que está em jogo. Seria preciso inventar novas ferramentas. Não que a literatura não tenha seu potencial ou que o próprio Foucault tenha mudado de posição em relação a ela. É que talvez ela não seja a forma mais viável ou sua abrangência na atualidade seja por demais limitada.

De qualquer modo, Foucault não abandona a linguagem nem a escrita. Continua falando e escrevendo, e torcendo as evidências para extrair delas novos sentidos. Talvez ele tenha deixado de falar de literatura para fazer literatura. Se afastado da ideia de transgressão para transgredir de outras maneiras. Fazer a própria língua gaguejar ou se tornar estrangeira, como diria Deleuze. Um Foucault dos múltiplos caminhos. Um Foucault trágico, por que não?

\section{Referências}

FOUCAULT, Michel. História da Loucura. Tradução de José Teixeira Coelho Netto. São Paulo: Editora Perspectiva, 1997, $5^{\text {a }}$ ed.

FOUCAULT, Michel. O nascimento da clínica. Tradução de Roberto Machado. Rio de Janeiro: Forense Universitária, $7^{\mathrm{a}}$ ed., 2013.

FOUCAULT, Michel. As Palavras e as Coisas: uma arqueologia das ciências humanas. Tradução de Salma Tannus Muchail. São Paulo: Martins Fontes, 1999.

FOUCAULT, Michel. Arqueologia do Saber. Tradução de Luiz Felipe Baeta Neves. Rio de Janeiro: Forense Universitária, $3^{\mathrm{a}}$ ed., 1987.

FOUCAULT, Michel. A ordem do discurso. Tradução de Laura Fraga de Almeida Sampaio. São Paulo: Loyola, $4^{\text {a }}$. ed., 1998.

FOUCAULT, Michel. Dits et écrits, I. Paris: Éditions Gallimard, 1994.

MACHADO, Roberto. Foucault, a filosofia e a literatura. Rio de Janeiro: Jorge Zahar Ed., 2000.

SALES, Márcio. Labirinto do trágico: Foucault e a experiência trágica da loucura. Rio de Janeiro: Achiamé, 2011.

SALES, Márcio. Caosmofagia: a arte dos encontros. Rio de Janeiro: Garamond, 2014.

VEYNE, Paul. Como se escreve a história e Foucault revoluciona a história. Brasília: Editora UnB, $4^{\mathrm{a}}$ ed., 1998. 